\title{
Pragmatism for Mixed Method Research at Higher Education Level
}

\author{
Gohar Saleem Parvaiz ${ }^{1}$, Owais Mufti², Muhammad Wahab
}

\begin{abstract}
Justifying mixed method approach through a philosophical paradigm is always a tough call, even for experienced researchers. In this regard, this research aims to justify the use of 'Pragmatism' supporting mixed method approach with the help of Laughlin (1995) matrix or methodological framework. For investigation, this research has used articulation approach; grounding essential theoretical information around pragmatism within Laughlin methodological framework to justify its use as a valid academic approach to mixed method research.
\end{abstract}

Keywords: Mixed method approach, pragmatism, Laughlin matrix.

\section{Introduction}

All researchers approach research site with some form of personal philosophical positioning which affects the way they see the world and the way they choose to conduct the research. In this regard, researchers often come across situations where they have to use 'mixed method' approach to investigate research phenomenon. However, in order to conduct a cohesive and sound research academically, researchers are required to support the use of mixed method with some form of methodological paradigm along with its ontological and epistemological justifications. A true researcher knows that supporting mixed method research within the ontological and epistemological believe system is not an easy task to do. This phenomenon led many $\mathrm{PhD}$ students to spend months of time to justify their research paradigm for their mixed method research. Therefore, this paper aims to address the question 'how to justify the use of pragmatism for mixed method research at higher education level?'

In order to justify the methodological approach of pragmatism for mixed method research, it is essential to understand its theoretical background. In this regard, the next section aims to provide a cohesive understanding on the methodological stance of 'pragmatism'.

1 Assistant Professor, Institute of Management Sciences, Peshawar. Email: gohar.saleem@imsciences. edu.pk

2 Assistant Professor, Institute of Management Sciences, Peshawar. Email: owais.mufti@imsciences.edu. pk

3 Content Writer, Centre for Excellence in Islamic Finance - SBP and UK DFID Project, Email: $m u$ hammadwahab55@gmail.com 


\subsection{Pragmatism}

'Pragmatism' is not new to social or management sciences. In literature there are some good reviews of pragmatism as a general belief system (see for example, Maxcy, 2003, Mackenzie \& Knipe, 2006; Tashakkori \& Teddlie, 2003; Somekh \& Lewin, 2005; Creswell, 2003). Pragmatism is an American methodological approach originating from the work of William James (1842-1910), John Dewey (1859-1952), Charles Sanders Peirce (1839-1914) and Herbert Mead (1863-1931). The word 'Pragma'

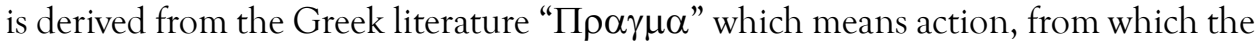
words 'practice' and 'practical' come (James, 2000). In English, the term 'pragmatic' has the connotation of searching for the feasible, workable solutions to complex human problems (Fishman, 1991). In academic literature, 'pragmatism' is defined as to "relieve and benefit the condition of man - to make mankind happier by enabling them to cope more successfully with the physical environment and with each other" (Rorty, 1991, p. 27). Thus the concern for a pragmatist is to find out 'what works' and what enables solutions to problems (Patton, 1990; Creswell, 2003). Pragmatist believes one should stop asking questions about the laws of nature and reality (ontology) and theory of knowledge (epistemology). For pragmatists, the research question or problem is the 'central' focus (Mackenzie \& Knipe, 2006; Creswell, 2003) where the central concern is 'what works' (Patton, 1990). According to Powell (2001):

The pragmatist proposes to reorient the assessment of theories around a third criterion: the theory's capacity to solve human problems (Rorty, 1989; Stich, 1990). To a pragmatist, the mandate of science is not to find truth or reality, the existence of which are perpetually in dispute, but to facilitate human problem-solving. According to pragmatist philosopher John Dewey, science should overthrow 'the notion, which has ruled philosophy since the time of the Greeks, that the office of knowledge is to uncover the antecedently real, rather than, as is the case with our practical judgments, to gain the kind of understanding which is necessary to deal with problems as they arise. (p. 884)

In order to academically justify the use of pragmatism for mixed method research, there is an essential requirement to have a logical flow from the choice of theory to the methodological dimension. In this regard, Laughlin (1995) matrix comes in as a life savior. The next section aims to provide a cohesive understanding on Laughlin (1995) matrix as a conceptual framework to address the underlying research question.

\subsection{Using Laughlin's (1995) Matrix or Methodological Framework as a Conceptual Framework}

Laughlin matrix (1995) allows academic researchers to position their philosophical 
paradigm and narrow down their choice of using research methods on a reasoned basis using theory, methodology, and change choice dimensions.

According to Laughlin (1995), every research process comprises of three broad dimensions labelled as "theory", "methodology", and "change" choices as presented in Figure 1.

(a) The 'theory choice' dimension on the x-axis in Figure 1 refers to the level of prior theorising that tends to shape the researcher's view about the nature of the world and what constitutes knowledge. As Laughlin (1995) states:

On the "theory" dimension we can express the amalgam of concern in relation to the level of prior theorizing and prior theories that can legitimately be brought to the empirical investigation. This links to ontological assumptions about the nature of the world we are investigating and our views about its materiality as well as its generality of representation through previous theoretical endeavours. (p. 66)

A 'High' level of prior theorisation (Figure 1) is an indication of an assumed material world, with a high level of generality that is already well achieved through a variety of empirical research. Another study in this regard is a little more than an incremental study that tends to test a well-developed theory.

Figure 1: Source: Laughlin (1995); 3D model of selecting research paradigm: 'theory-choice' on $\mathrm{x}$-axis, 'methodology-choice' on y-axis and 'change-choice' on z-axis.

\begin{tabular}{|c|c|c|c|c|}
\hline & \multicolumn{4}{|c|}{ Theory Choice: Levels of Prior Theorisation } \\
\hline & & High & Medium & Low \\
\hline \multirow[t]{3}{*}{$\begin{array}{l}\text { Methodological } \\
\text { choice: levels of } \\
\text { theoretical nature } \\
\text { of methods }\end{array}$} & High & $\begin{array}{c}\text { Positivism (L) } \\
\text { Realism (L) } \\
\text { Instrumentalism (L) } \\
\text { Conventionalism (L) }\end{array}$ & & \\
\hline & Medium & & $\begin{array}{l}\text { German critical } \\
\text { Theory (M) }\end{array}$ & $\begin{array}{c}\text { Symbolic Interactionism } \\
\text { (Kuhn) (L) }\end{array}$ \\
\hline & Low & Marxism (H) & $\begin{array}{l}\text { Structuration (L) } \\
\text { French Critical } \\
\text { Theory (L) }\end{array}$ & $\begin{array}{c}\text { Pragmatism (L) } \\
\text { Symbolic Interactionism } \\
\text { (Blumer) (L) } \\
\text { Ethnomethodology (L) }\end{array}$ \\
\hline
\end{tabular}

Change choice: Level of emphasis given to critique of status quo and need for change (High/Medi$\mathrm{um} / \mathrm{Low})(\mathrm{H}, \mathrm{M}, \mathrm{L})$ 
A 'Medium' level of theory (Figure 1), as stated by Laughlin:

...recognizes that generalizations about reality are possible, even though not guaranteed to exist, yet maintains that these will always be "skeletal" requiring empirical detail to make them meaningful...to "middle range" thinkers the empirical detail is of vital importance. It complements and completes the "skeletal" theory" (p. 81)

A 'Low' level of theory choice (Figure 1) at the extreme assumes that the world is not material (being a projection of the mind). Equally, learning from or relying on previous theoretical studies and insights is both inappropriate and potentially corrupting of the diversity and detail of an investigation. In this regard Laughlin states:

In this position the empirical detail is not mere confirmable or refutable "data" for some prior theory but becomes important in its own right. This detail becomes the theory for this particular phenomena but cannot be transferred to another study for the reasons that other theories could not be used in the context of this study - both are separate and distinct and should be approached as such. (p. 66-67)

(b) The 'Methodology choice' dimension on y-axis in Figure 1 refers to the way of conducting an investigation which can either rely on the implicit perceptual power of the researcher or could be defined by the theoretical approach towards the observed phenomenon.

A methodology choice is categorised as 'High' (Figure 1) when a method is adopted whereby there is high theoretical definition. In this case, the role of the researcher becomes independent of the phenomenon which is being researched. Hence, researcher subjectivity plays no part in such research processes.

At a 'Medium' level of methodology choice (Figure 1), the intention of the researcher is to design a methodological approach which sets the 'skeletal' rules for the discovery process. A 'Medium' level allows for diversity in the observational process. At this level there is a combination of both high and low level methodological extremes while avoiding their weaknesses.

At a 'Low' level of methodology choice (Figure 1), the researcher is allowed to be involved in the observation process and is permitted to preserve his/her subjectivity completely. At this level the methodological approach has no pre-defined theoretical definitions for the interpretation of the resultant outcome.

(c) The 'Change choice' dimension in Figure 1 refers to the researcher's attitude concerning the worth of maintaining the status quo in what is being investigated. At the 'High' end of the change dimension the researcher views everything as inadequate 
and incomplete and feels immediate need for change, though he or she is not always in a position to engender the required change. On the other extreme, the 'Low' end of the change choice dimension, researchers see little problem in maintaining the status quo.

At the 'Middle' level of the change dimension, researchers adopt a strategic attitude to change, being open to certain aspects of current functioning but at the same time to also challenging the status quo.

Figure 2 shows the theoretical and methodological dimensions in the diagonal of Figure 1 (Laughlin, 2004). In Figure 2 the diagonal represents the high/high position (top left) to the low/low position (bottom right) of the theoretical and methodological dimensions respectively, as one moves from left to right. The content of this high/ high, medium/medium, and low/low diagonal can be exposed in the related six horizontal headings from top to bottom in Figure 2 (Laughlin, 2004). The first two horizontal headings relate to theory whereas the lower four relate to methodology. The arrows in the figure represent the primacy of ontology that links the tendency to rely on prior theory or not, as the case may be. At the bottom of Figure 2 is the

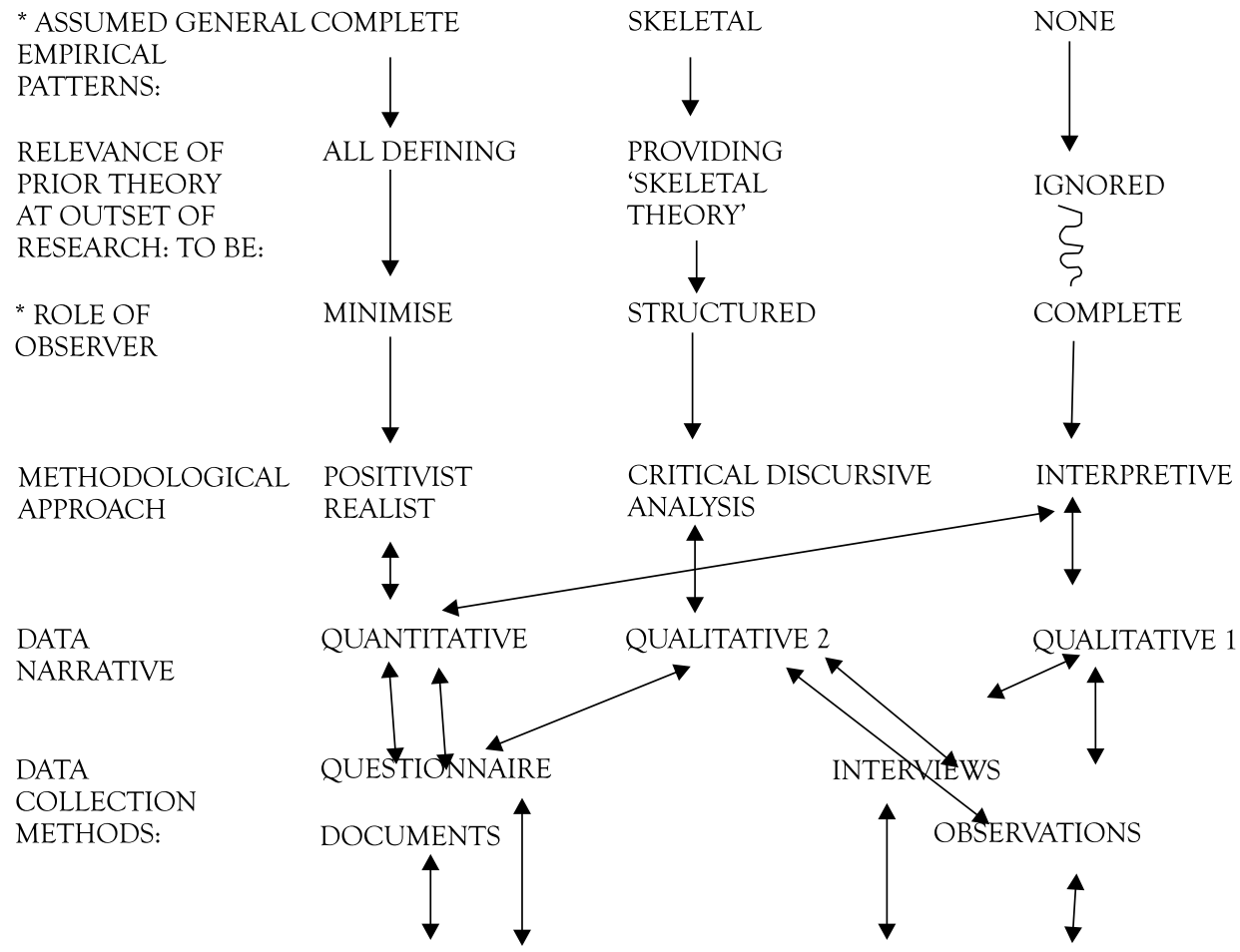

Organisations and Societies made up of People and Non-Human Phenomenon Figure 2: Source: Laughlin (2004); representing theoretical and methodological dimensions 
targeted phenomenon.

All researchers approach research site with some form of personal philosophical positioning which affects the way they see the world and the way they choose to conduct the research (Laughlin, 1995). Once the decision on ontological and theoretical choice is made, then it has implications for the role of the observer. According to Laughlin (2004) if empirical patterns can be summarized in theoretical terms and concepts (such as hypotheses), then during the investigation researcher bias is minimised and the subjectivity associated with it. The distinction between 'minimum' and 'complete' subjectivity is easy to conceptualise. 'Minimum' subjectivity considers the observer as being largely independent of the investigated phenomenon and therefore the observer value biasness is largely avoided. Whereas with 'complete' subjectivity the observer is important and always a part of the discovery process (Laughlin, 1995). The mid position between minimum and complete is associated with a 'skeletal' theoretical stance and an observer position of 'structured' subjectivity in respect of the research site. In Figure 2, 'structured' subjectivity tries to specify more precisely abstracted terms and concepts whilst not trying to squeeze out the intuitive, imaginative properties of individual observer (Laughlin, 2004).

Once the role of the researcher is decided then it has implications for the choice of methodological approach. In Figure 2, minimum subjectivity tends to be associated with methodological approaches such as positivism, realism, instrumentalism and conventionalism. Where there is complete subjectivity, this tends to be associated with methodological approaches such as grounded theory, ethnomethodology, symbolic interactionism (Blumer/Kuhn) and pragmatism. In the middle position structured subjectivity tends to be associated with methodological approaches such as structuration, German critical theory, French critical theory, and Marxism.

Finally, the last two levels in Figure 2 involve incorporating data collection methods. Generally, there are four methods which are usually employed to collect the data: questionnaires, interviews, documents (articulation) and observations. But here, it is cautiously important to generate data in those narratives (quantitative and qualitative) which must be in accordance with the philosophical paradigm of the adopted methodological approaches.

The next section, aims to describe methodology of this paper that has been adopted to address the underlying research question.

\section{Methodology}

From the methodological perspective, this paper has employed the articulation technique. Articulation technique allows one to logically build the argument in ref- 
erence to the available literature or data to address the research problem/question. In this research, philosophical arguments from previous literatures that serve as a secondary data is grounded within Laughlin's (1995) methodological framework's defined theory, methodological, and change choice dimensions to justify the use of pragmatism for mixed method researches.

The following established literature is reviewed and key arguments from it are

Table 1: Representing literature that is reviewed and key arguments from it are used within Laughlin (1995) matrix

\begin{tabular}{|c|c|c|c|}
\hline S. No. & Author/Date & Articles/Books/thesis & Publisher \\
\hline 1 & $\begin{array}{l}\text { Morgan, D.L. } \\
\text { (2007) }\end{array}$ & $\begin{array}{c}\text { Paradigms lost and pragmatism } \\
\text { regained }\end{array}$ & $\begin{array}{l}\text { Journal of mixed methods } \\
\text { research }\end{array}$ \\
\hline 2 & Patokorpi, E. (2006) & $\begin{array}{l}\text { Role of abductive reasoning in } \\
\text { digital interaction }\end{array}$ & Åbo Akademi University \\
\hline 3 & Powell, T.C. (2001) & $\begin{array}{c}\text { Competitive advantage: Logical } \\
\text { and philosophical consider- } \\
\text { ations }\end{array}$ & Strategic Management Journal \\
\hline 4 & Pansiri, J. (2005) & $\begin{array}{l}\text { Pragmatism: A methodological } \\
\text { approach to researching strategic } \\
\text { alliances in tourism }\end{array}$ & $\begin{array}{l}\text { Tourism and Hospitality Plan- } \\
\text { ning \& Development }\end{array}$ \\
\hline 5 & $\begin{array}{l}\text { Creswell, J.W. } \\
\text { (2003) }\end{array}$ & $\begin{array}{l}\text { Research design: Qualitative, } \\
\text { quantitative, and mixed meth- } \\
\text { ods approaches }\end{array}$ & Thousand Oaks: Sage \\
\hline 6 & $\begin{array}{l}\text { Mackenzie, N. and } \\
\text { Knipe, S. (2006) }\end{array}$ & $\begin{array}{l}\text { Research dilemmas: Paradigms, } \\
\text { methods and methodology }\end{array}$ & Issues in Educational Research \\
\hline 7 & Laughlin, R. (1995) & $\begin{array}{l}\text { Empirical research in account- } \\
\text { ing: alternative approaches } \\
\text { and a case for "middle-range" } \\
\text { thinking", Accounting, Auditing } \\
\text { \& Accountability Journal }\end{array}$ & $\begin{array}{l}\text { Accounting, Auditing \& Ac- } \\
\text { countability Journal }\end{array}$ \\
\hline 8 & Laughlin, R. (2004) & $\begin{array}{l}\text { Putting the record straight: a } \\
\text { critique of methodology choices } \\
\text { and the construction of facts: } \\
\text { some implications from the } \\
\text { sociology of knowledge }\end{array}$ & $\begin{array}{l}\text { Critical Perspectives on Ac- } \\
\text { counting }\end{array}$ \\
\hline
\end{tabular}

picked and employed within Laughlin (1995) matrix (see Table 1):-

The next section aims to incorporate key arguments from the reviewed literature (see Table 1) within Laughlin's (1995) methodological framework's defined theoretical, methodological, and change choice dimensions. 


\section{Justifying the Use of Pragmatism for Mixed Method Research}

In Laughlin (1995) matrix, 'connection of theory' is one of the prominent features for the adoption of an appropriate methodological approach for the research.

In positivism, the aim is to use deductive reasoning where the objective of the researcher is to confirm often a well-established theory employing primary data analysis. On the other hand, the interpretive approach often draws upon inductive reasoning where the objective is to develop a theory. This sharp distinction between the reasoning process of positivism and interpretivism places both of these approaches at the opposite extremes on a research process continuum. But here, as any experienced researcher knows, in reality the research design is not so polarised (Morgan, 2007). With pragmatism the researcher will typically employ an 'abductive' reasoning process which moves back and forth between an inductive and a deductive reasoning process (Morgan, 2007). This abduction process is defined as a "retroductive process (the spontaneous conjectures of instinctive reason) of finding or forming hypotheses or theories that might explain a (surprising) fact or an (unexpected) observation" (Patokorpi, 2006, p. 73). In regard to 'pragmatism', Powell (2001) stated:

The pragmatist epistemology stands in contrast to prevailing positivist and anti-positivist views of scientific discovery. Whereas positivism emphasizes the objective, law-like properties of a brute reality independent of observation (Donaldson, 1992; Wicks \& Freeman, 1998), anti-positivism emphasizes the creative role of active, subjective participants, none of whom owns a privileged claim on truth (Burrell \& Morgan, 1979; Astley, 1985; Martin, 1990). Pragmatism, on the other hand, rejects positivism, on grounds that no theory can satisfy its demands (objectivity, falsify-ability, the crucial experiment, etc.); and rejects anti-positivism, because virtually any theory would satisfy them. (p. 884)

In consideration to Powell (2001) arguments, Figure 3 is a revised version of Figure 2 representing epistemological stance of 'pragmatism' within Laughlin's (1995) methodological framework, i.e. a 'Low/Low' positioning in Figure 2. This 'Low/Low' positioning in respect of the theory and methodological choices have already been explained in previous sections. At a 'Low' level of theory there is no clear replicable information available to feed into a prior theory for the evaluation purpose (Laughlin, 2004). This is certainly the case with the epistemological beliefs of pragmatism as earlier explained by Powell (2001) above.

With a 'Low' methodology, Laughlin (2004) asserts a 'complete' reliance on the observer's subjectivity. That is why Figure 3 is showing the wavy line rather than an arrowed line, thus depicting the divorce between the theory and methodology dimen- 


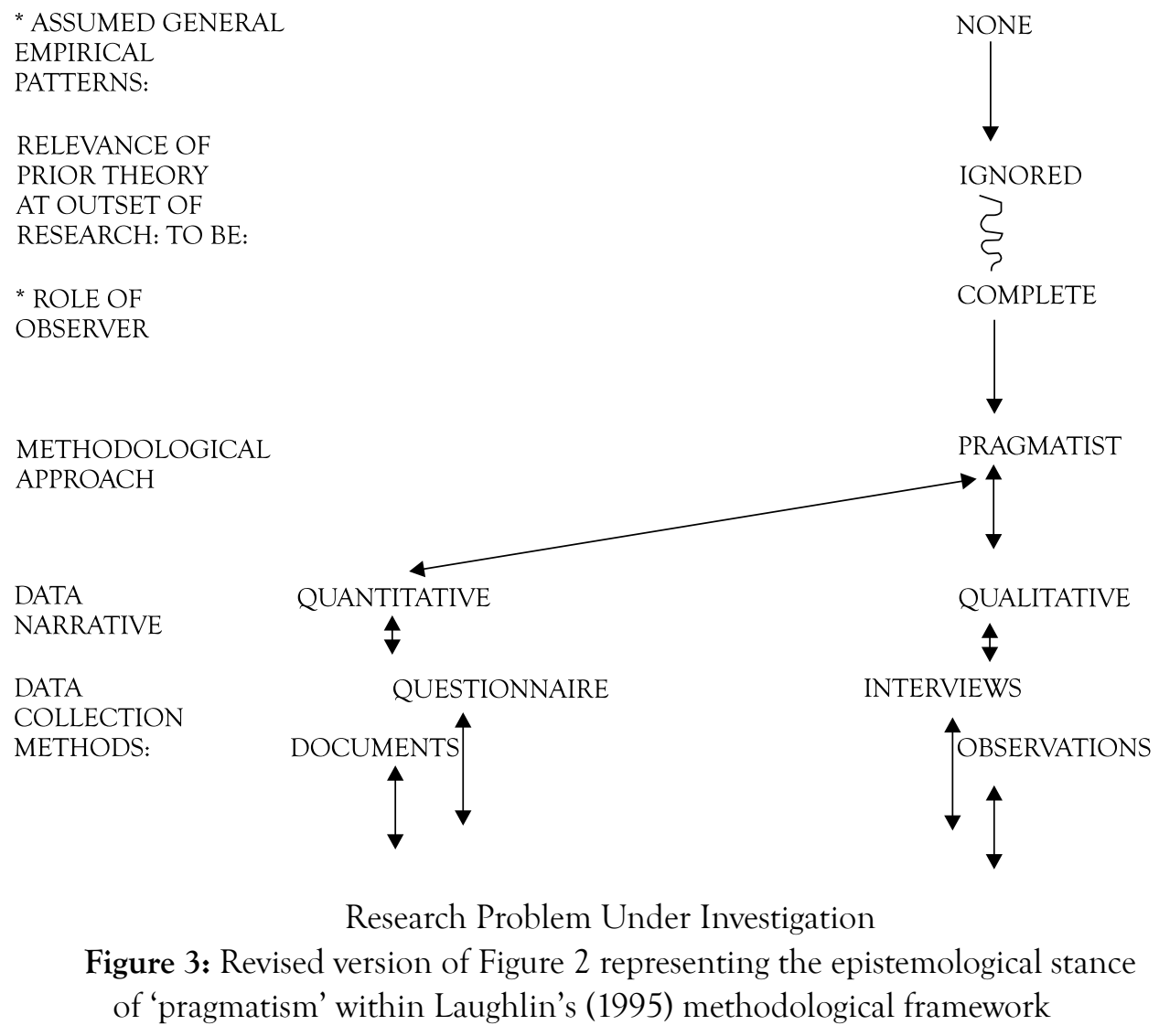

sions. However, pragmatists believe that there is a "real world" out there, but at the same time they also believe that all individuals have their own unique interpretations of that world (Morgan, 2007). Thus a pragmatist may decline to accept or rely on his/her complete 'subjectivity' and instead adopt the notion of 'inter-subjectivity'. For-example, as Pansiri (2005) stated, "for pragmatists, values play an important role in conducting research and interpreting results, and the researcher is advised to accept external reality and choose explanations that best produce desired outcomes" (p. 198).

Also, the point to examine is the Kantian/Fictean line in Figure 4 which has branches through Wilhelm Dilthey's (1833-1911) and Max Weber's (1864-1920) schools of thought. Both schools of thought can be regarded as keys in providing objective but also subjective dimensions where pragmatism lies. This allows researchers to use the notion of inter-subjectivity to capture the duality (subjectivity/objectivity stance) of a phenomenon before representing it as a social reality (Morgan, 2007). For example, as Pansiri (2005) stated: 
In terms of the mode of enquiry, pragmatism embraces the two extremes normally espoused by positivism/post-positivism and those supported by interpretivists. The former emphasizes quantitative methods as opposed to interpretivists' qualitative approaches. Not surprisingly therefore pragmatism has been hailed as the foundation of mixed-method research (Tashakkori \& Teddlie, 1998; Teddlie \& Tashakkori, 2003, p. 197)

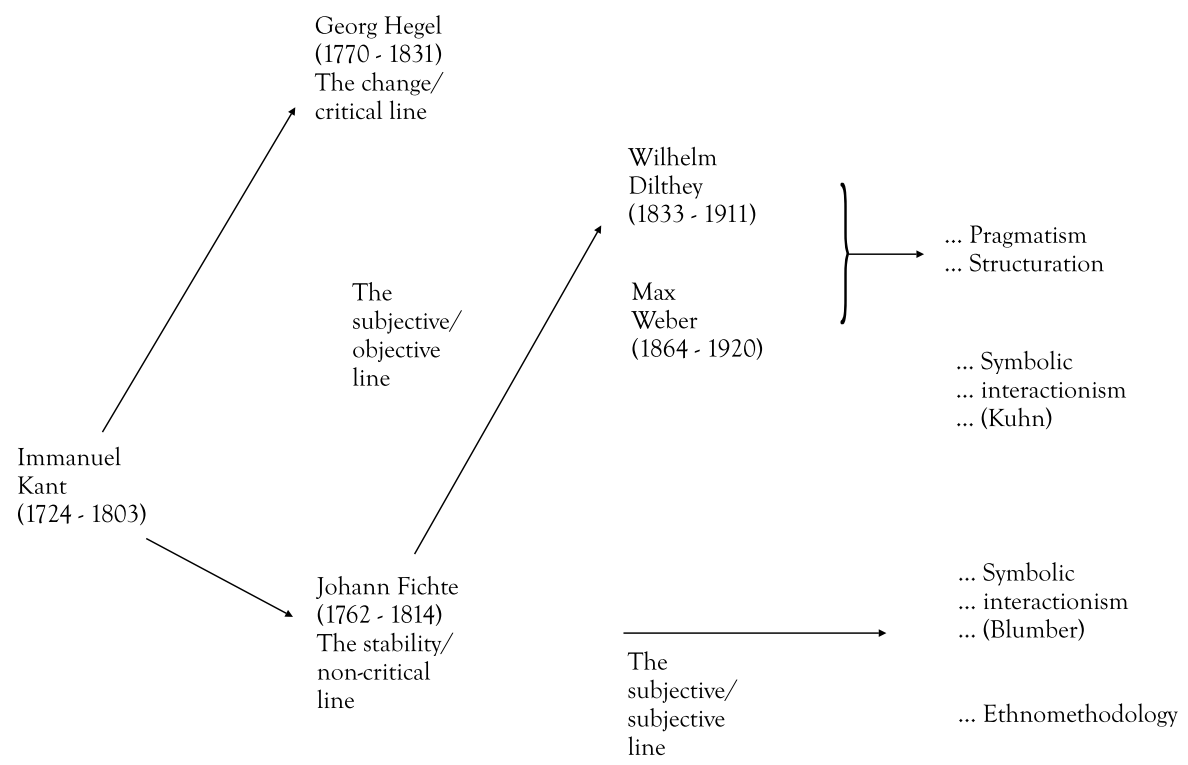

Figure 4: Source Laughlin (1995, p. 66)

In Figure 3, in terms of 'data narrative' and 'data collection method', the rationale for the adoption of pragmatism links directly to the purpose and the nature of the research problem which is being posed (Creswell, 2003). In pragmatism, instead of the method being dominant, the research problem is viewed as the most important concern (Creswell, 2003). Thus the adopted data collection methods (interview, questionnaires, observation and articulation/documentation etc.), narratives (qualitative and quantitative), and the analysis (descriptive, factor, content, thematic and discourse etc.) are deemed to be the most likely factors to provide a deep insight into the research problem (Creswell, 2003; Mackenzie \& Knipe, 2006). Thus, pragmatism explicitly hails the foundations for the mixed method researcher.

\section{Conclusion}

Previously, detailed theoretical links were missing in regards to pragmatism which could justify its use as a valid methodological approach for mixed method researches. In this research, prior literature around pragmatism is grounded within Laughlin's 
(1995) methodological framework's defined theoretical, methodological and change choice dimensions to provide evidence for the use of 'pragmatism' as a valid approach for mixed method researches. This systematic connection of prior literature within Laughlin (1995) matrix explicitly unveiled the ontological, epistemological, axiological, and methodological stance of pragmatism. This surely can help the naïve researchers to ground their understanding. By referencing to this research and particularly 'Section 3' of this paper, now academic researchers can confidently use pragmatism for mixed method researches.

\section{References}

Astley G. (1985). Administrative science as socially constructed truth. Administrative Science Quarterly, 30(4), 497-513.

Burrell G., \& Morgan, G. (1979). Sociological paradigms and organizational analysis. London: Heinemann Educational Books.

Creswell, J. W. (2003). Research design: Qualitative, quantitative, and mixed methods approaches, (2nd ed.). Thousand Oaks: Sage Publications.

Donaldson, L. (1992). The Weick stuff: Managing beyond games. Organizational Science, 3(4), 461-466.

Fishman, D. B. (1991). An introduction to the experimental versus the pragmatic paradigm in evaluation. Evaluation and Program Planning, 14(4), 353-363.

James, W. (2000). What pragmatism means. In J. J. Stuhr (Eds.), Pragmatism and classical American philosophy: Essential readings and interpretive essays. (pp. 193-202). New York, NY: Oxford University Press.

Laughlin, R. (1995). Empirical research in accounting: Alternative approaches and a case for "middle-range" thinking. Accounting, Auditing $\mathcal{E}$ Accountability Journal, 8(1), 63-87.

Laughlin, R. (2004). Putting the record straight: A critique of methodology choices and the construction of facts: some implications from the sociology of knowledge. Critical Perspectives on Accounting, 15(2), 261-277.

Mackenzie, N., \& Knipe, S. (2006). Research dilemmas: Paradigms, methods and methodology. Issues in Educational Research, 16(2), 193-205.

Martin, J. (1990). Deconstructing organizational taboos: The suppression of gender conflict in organizations. Organization Science, 1(4), 339-359.

Maxcy, S.J. (2003). Pragmatic threads in mixed methods research in the social sciences: The search for multiple modes of inquiry and the end of the philosophy of formalism. In A. Tashakkori \& C. Teddlie (Eds.), Handbook of mixed methods in the social and behavioral sciences. (pp. 51-89). Thousand Oaks: Sage Publications. 
Morgan, D. L. (2007). Paradigms lost and pragmatism regained. Journal of Mixed Methods research, 1(1), 48-76.

Pansiri, J. (2005). Pragmatism: A methodological approach to researching strategic alliances in tourism. Tourism and Hospitality Planning $\mathcal{E}$ Development, 2(3), 191-206.

Patokorpi, E. (2006). Role of abductive reasoning in digital interaction. Unpublished PhD Dissertation, Åbo Akademi University, Finland.

Patton, M. Q. (1990) Qualitative evaluation and research methods. Sage Publications, Inc.

Powell, T. C. (2001). Competitive advantage: Logical and philosophical considerations. Strategic Management Journal, 22(9), 875-888.

Rorty, R. (1989). Contingency, irony and solidarity. New York, NY: Cambridge University Press.

Rorty, R. (1991). Essays on Heidegger and others. New York, NY: Cambridge University Press.

Somekh, B., \& Lewin, C. (2005) Research methods in the social sciences. London: Sage Publications.

Stich S. (1990). The Fragmentation of reason. Cambridge, (MA): MIT Press.

Tashakkori, A., \& Teddlie, C. (1998). Mixed methodology: Combining qualitative and quantitative approaches. Thousand Oaks, CA: Sage Publications.

Tashakkori, A., \& Teddlie, C. (2003). Handbook of mixed methods in social $\mathbb{E}$ behavioral research. Thousand Oaks: Sage Publications.

Wicks, A., \& Freeman, R. (1998). Organization studies and the new pragmatism: Positivism, anti-positivism, and the search for ethics. Organization Science, 9(2), 123-140. 